\title{
BMJ Open Are there any differences between different testing sites? A cross-sectional study of a Norwegian low-threshold HIV testing service for men who have sex with men
}

Bera Ulstein Moseng, Vegar Bjørnshagen

To cite: Moseng BU, Bjørnshagen V. Are there any differences between different testing sites? A cross-sectional study of a Norwegian low-threshold HIV testing service for men who have sex with men. BMJ Open 2017;7:e017598. doi:10.1136/ bmjopen-2017-017598

- Prepublication history for this paper is available online. To view these files, please visit the journal online (http://dx.doi. org/10.1136/bmjopen-2017017598).

Received 5 May 2017 Revised 28 August 2017 Accepted 31 August 2017
CrossMark

Gay and Lesbian Health Norway, Oslo, Norway

Correspondence to

Vegar Bjørnshagen;

vegar.bjornshagen@gmail.com

\section{ABSTRACT}

Objective To describe a Norwegian low-threshold HIV testing service targeting men who have sex with men (MSM).

Design and setting After the HIV testing consultation, all users of the HIV testing service were invited to answer the study questionnaire. The study setting included the sites where testing was performed, that is, the testing service's office in 0slo, cruising areas, bars/clubs and in hotels in other Norwegian cities.

Participants MSM users of the testing service. Primary and secondary outcome measures Data were collected on demographics, HIV testing and sexual behaviour as well as the participant's motivations for choosing to take an HIV test at this low-threshold HIV testing service. The data are stratified by testing site. Results 1577 HIV testing consultations were performed, the study sample consisted of 732 MSM users. 11 tested positive for HIV. $21.7 \%$ had a non-western background, $27.1 \%$ reported having a non-gay sexual orientation. $21.9 \%$ had 10 or more male sexual partners during the last year, $27.9 \%$ reported also having had a female sexual partner. $56.4 \%$ reported having practised unprotected anal intercourse during the last 6 months. $20.1 \%$ had never tested for HIV before. Most of these user characteristics varied by testing sites.

Conclusions The Norwegian low-threshold testing service recruits target groups that are otherwise hard to reach with HIV testing. This may indicate that the testing service contributes to increase HIV testing rates among MSM in Norway.

\section{INTRODUCTION}

In Norway, as in other Western countries, men who have sex with men (MSM) are disproportionately affected by HIV and other sexually transmitted infections (STIs). ${ }^{1-3}$ There is reason to believe that a significant proportion of MSM are not being reached with traditional modes of offering HIV testing. Strategic approaches, like HIV testing in non-clinical settings can be a response to this situation. During the
Strengths and limitations of this study

- The study sample is recruited by self-selection.

- The study relies on self-reported data on sexual behaviour, which can be subject to recall and desirability bias.

- The study has a high response rate $(79 \%)$ and the sample is heterogeneous.

last decade, HIV testing services outside the ordinary healthcare system have been established in several European countries. ${ }^{4-7}$ Most of these testing services for MSM are organised by community-based organisations using healthcare providers such as nurses or doctors, but some use trained lay providers and aim for a more neutral profile. Sjekkpunkt Norway is an example of the last mentioned strategy.

Sjekkpunkt Norway takes a low-threshold approach to HIV testing targeting MSM. The low-threshold approach is ensured by a high degree of availability and that the service is convenient, anonymous and discrete as well as being administered by peers, in this case other MSM working as trained lay providers, that is, not health personnel. In charge of the service is Gay and Lesbian Health Norway (GLHN), a non-governmental organisation that has worked with HIV prevention in Norway since 1983. The testing service was launched as a pilot in December 2012 as a cooperation project between GLHN, Oslo Municipality and the Norwegian Directorate of Health.

In the present situation, the low HIV testing rates among MSM constitute a considerable challenge. ${ }^{8} 9$ According to Clifton et $a l,{ }^{10}$ some MSM do not test for HIV despite perceiving themselves as being 'greatly' or 'quite a lot' at risk. Furthermore, 
the study shows that other MSM who had not tested for HIV did not perceive their reported risk behaviour as being risky behaviour. ${ }^{11}{ }^{12}$ In 2014, The Norwegian Institute of Public Health estimated that between 500 and 700 individuals (ie, $15 \%$ of all HIV positive people in Norway) live with HIV without knowing their HIV status. ${ }^{13}$ This high number of individuals living with HIV without knowing their status does not match with with Norwegian data from non-representative Internet studies indicating that approximately 7 out of 10 have taken an HIV test. ${ }^{14} 15$ British and American population-based studies, recruiting more broadly from the MSM population, suggest that the proportion of MSM that have ever been tested for HIV is lower, between $50 \%$ to $60 \%$, and that between $15 \%$ to $35 \%$ take a yearly test. ${ }^{1112161718}$

To increase testing in the MSM population, establishing a wide range of testing services as diverse as the individuals constituting this sexual minority is crucial. These different HIV testing services should address barriers to HIV testing. Sjekkpunkt Norway is designed to address such barriers. Of importance can be mobility, availability and convenience (ie, opening hours, the use of rapid tests, being present at venues where MSM meet, such as sex clubs and gay bars) and ensuring anonymity and discretion in the HIV testing situation. ${ }^{19}{ }^{20}$ Sjekkpunkt Norway is an anonymous service because you can get tested without stating your name or social security number. The office in Oslo is located in a building with other organisations and companies, which means that a visit to the building does not imply that you are there to test for HIV, with all the possible connotations this may entail. An overall aim is also to appear as neutral as possible, without a gay or a lesbian, gay, bisexual, and transgender (LGBT) profile, which may be of importance for hard-to-reach groups such as men who have sex with both men and women (MSMW) and MSM with non-western immigrant backgrounds. ${ }^{21}{ }^{1}$ The peer-topeer approach is also meant to lower the threshold of taking an HIV test. That MSM test other MSM might enable an open, non-judgemental and non-clinical conversation about HIV risk factors. ${ }^{4}$ Furthermore, the peer-administered approach is a precondition for access to MSM-only venues, such as gay saunas and cruising areas, which are important target venues for the outreach part of the project.

The objective of this study is to describe a low-threshold HIV testing service for MSM, in this case Sjekkpunkt Norway, and to present the HIV testing behaviour, the demographic and sexually behavioural characteristics of the service's users, depending on the site on which they were tested. The hypothesis is that a low-threshold testing service with characteristics like those of Sjekkpunkt Norway (availability, being mobile, anonymity and discretion, neutrality, peer-to-peer approach, etc) could reach high risk groups within the MSM population (ie, MSMW and MSM with non-western immigrant backgrounds), MSM with high-risk behaviour (such as practising unprotected anal intercourse (UAI) and having a higher number of sexual partners) and MSM rarely or not testing for HIV in the ordinary healthcare system.

\section{Methods}

\section{Ethics statement}

This study was approved and considered not being notifiable by the Norwegian Centre for Research Data and the Regional Committees for Medical and Health Research Ethics. The survey was anonymous, and informed consent was obtained by the participants clicking 'OK' when entering the electronic questionnaire after having read the introduction to the survey. This introduction contained information describing the aims and dissemination of the study results.

\section{Study population and data collection}

In the study period between February 2015 and February 2016, Sjekkpunkt Norway offered HIV testing on the following locations: in the GLHN office every Monday to Saturday, as well as at a gay sauna on a weekly basis and occasionally on other MSM sex venues (cruising areas, fetish clubs, etc) in Oslo, gay bars and clubs and in hotels in other major Norwegian cities such as Stavanger, Bergen and Trondheim. The study sites include all these locations.

This article is based on data reported by the users of Sjekkpunkt Norway. The project targets MSM, but regardless of gender, sexual orientation and age, everyone that approached the testing service during the study period was offered an HIV test. After being tested for HIV, all the users were invited to participate in the study. They would then fill out an electronic questionnaire on one of the project's tablets if they met the inclusion criteria of being 18 years or older and agreeing to participate in the study. The study sample was then restricted to male respondents who reported having had sexual relations with men.

\section{Questionnaire}

The questionnaire included validated measures on sexual behaviour and sexual orientation tested in representative studies regarding sexual health, like The National Survey of Sexual Attitudes and Lifestyles (Natsal), National Health and Nutrition Examination Survey (NHANES) and The National Longitudinal Study of Adolescent to Adult Health (Add Health). The questionnaire also included tested measures on alcohol and drug use, HIV testing behaviour and history of other STIs.

\section{Data analysis}

Stratified by testing site, the sample's distribution on the following variables is presented: age, sexual orientation, HIV testing history, place of birth, number of male sexual partners during the last year, number of female sexual partners during the last year and risk sex measured as UAI with one or more casual sex partner(s) during the last 6 months. 
Based on where participants reported being tested, the variable testing site was operationalised as follows: participants being tested at a sauna or on a cruising area were grouped together, also grouped together were participants being tested at a festival or in a gay bar/ club. Further, participants being tested in the GLHN office were grouped together as were participants being tested in hotel rooms. $\chi^{2}$ tests were used to compare differences between the four groups. Statistical significance was defined as $\mathrm{p}<0.10$ due to the small sample size and the small number of respondents making up the groups being compared.

The study participants motivations for choosing to take an HIV test at Sjekkpunkt Norway specifically are also described.

Statistical analyses were performed using SPSS V.23.

Results

During the study period, Sjekkpunkt Norway was visited (ie, not unique users) a 1577 times. The survey was answered 1246 times (ie, not unique users). After excluding respondents reporting being women, trans persons, men who have sex exclusively with women and respondents that visited the testing service twice or more during the study period, as well as three MSM not reporting testing site, the study sample consists of 732 respondents.

Of the 1577 consultations, 11 users tested positive for HIV. Of the individuals testing positive for HIV, nine were linked to care at an infectious diseases ward. Seven of the users got their positive result in the office of Sjekkpunkt Norway, of which all were linked to medical care at an infectious diseases ward either the same or the following day. The rest of the users that tested positive got their result; at a gay sauna, in a hotel, in a gay bar and in a recreational vehicle outside a gay club. All were linked to care within the following week, except two users, one of whom preferred to go to his general practitioner and the other, who was a tourist, who would seek medical care in his country of residence. In total, 70 MSM were diagnosed with HIV in Norway in 2015, which means Sjekkpunkt Norway tested approximately $15 \%$ of the reported HIV cases among MSM this year. ${ }^{22}$ Thirteen users received reactive syphilis test results and were recommended to attend a sexual health clinic to get treatment.

Table 1 shows that the majority of the users were 49 years or younger, that every fifth user $(21.7 \%)$ had a non-western immigrant background (ie, not being born in Norway or elsewhere in Western Europe or North

\begin{tabular}{|c|c|c|c|c|c|c|}
\hline & Sauna/cruising & Gay bars/clubs & GLHN office & Hotel & Total & $p$ \\
\hline Age & & & & & & $<0.001$ \\
\hline 16-24years & $13.5(14)$ & $24.3(17)$ & 24.5 (105) & $31.8(41)$ & $24.2(177)$ & \\
\hline 25-34 years & $22.1(23)$ & 25.7 (18) & 37.8 (162) & $31.8(41)$ & $33.3(244)$ & \\
\hline $35-49$ years & $33.6(35)$ & 35.7 (25) & $25.6(110)$ & $22.5(29)$ & 27.2 (199) & \\
\hline 50-59years & $23.1(24)$ & $8.6(6)$ & $8.2(35)$ & $7.0(9)$ & $10.1(74)$ & \\
\hline$\geq 60$ years & $7.7(8)$ & $5.7(4)$ & $4.0(17)$ & $7.0(9)$ & $5.2(38)$ & \\
\hline Place of birth & & & & & & 0.25 \\
\hline Norway & $64.4(67)$ & $70.0(49)$ & $63.9(274)$ & $75.2(97)$ & $66.5(487)$ & \\
\hline Western Europe & $12.5(13)$ & $8.6(6)$ & $9.8(42)$ & $7.0(9)$ & $9.6(70)$ & \\
\hline Eastern Europe & $6.7(7)$ & $2.9(2)$ & $5.6(24)$ & $3.9(5)$ & $5.2(38)$ & \\
\hline North America & $1.0(1)$ & $1.4(1)$ & $2.6(11)$ & $3.1(4)$ & $2.3(17)$ & \\
\hline South America & $1.0(1)$ & $7.1(5)$ & $3.5(15)$ & $3.9(5)$ & $3.6(26)$ & \\
\hline Middle East & $5.8(6)$ & $2.9(2)$ & $1.9(8)$ & $1.6(2)$ & $2.5(18)$ & \\
\hline Asia/Oceania & $6.7(7)$ & $7.1(5)$ & $10.5(45)$ & $4.7(6)$ & $8.6(63)$ & \\
\hline Africa & $1.9(2)$ & $0.0(0)$ & $2.3(10)$ & $0.8(1)$ & $1.8(13)$ & \\
\hline Sexual orientation & & & & & & 0.25 \\
\hline Gay & $73.1(76)$ & $82.6(57)$ & 72.0 (309) & $64.3(83)$ & 71.8 (525) & \\
\hline Bisexual & $19.2(20)$ & $13.0(9)$ & $17.0(73)$ & $26.4(34)$ & $18.6(136)$ & \\
\hline Straight & $2.9(3)$ & $1.5(1)$ & $5.6(24)$ & $4.6(6)$ & $4.7(34)$ & \\
\hline Queer & $1.9(2)$ & $1.5(1)$ & $0.7(3)$ & $1.6(2)$ & $1.1(8)$ & \\
\hline Unsure & $2.9(3)$ & $1.5(1)$ & $4.7(20)$ & $3.1(4)$ & $3.8(28)$ & \\
\hline $\mathrm{N}$ & 104 & 70 & 429 & 129 & 732 & \\
\hline
\end{tabular}

${ }^{*} \mathrm{~N}$ and percentages for a given variables may not sum to column total due to missing values.

GLHN, Gay and Lesbian Health Norway. 
America) and that $27.1 \%$ reported having a non-gay sexual orientation (ie, straight, bisexual or unsure). These demographic characteristics differed by testing site. Users getting tested at a sauna/on cruising areas were generally older ( $30.8 \%$ above 50 years) compared with users on the other testing sites. Considering place of birth, users being tested at hotels were less likely to report a non-western background. The hotel users also stand out regarding sexual orientation, with the lowest proportion of users reporting being gay (64.3\%), compared with the users on the other testing sites. However, the differences in place of birth and sexual orientation between users at different testing sites were not statistically significant.

Table 2 shows that every fifth user of Sjekkpunkt Norway $(21.9 \%)$ had 10 or more male sexual partners during the last year. $27.9 \%$ reported also having had a female sexual partner during the same period of time. Furthermore, $56.4 \%$ of the users reported having practised UAI with one or more male sexual partner(s) during the last 6 months. Regarding HIV testing history, $20.1 \%$ reported never having tested for HIV earlier, $13.8 \%$ had not tested for HIV during the last 2 years. Like the social demographics, the sexually behavioural characteristics also varied according to testing site. A larger proportion of users getting tested at a sauna/ on a cruising area $(30.8 \%)$ reported 10 or more male sexual partners, compared with users of other testing sites, especially those testing at the GLHN office, where only $18.0 \%$ reported as many male sexual partners the last year $(p=<0.10)$. Concerning differences in reporting having practised UAI with one or more partner(s), users getting tested at hotels differ with having the largest proportion $(68.2 \%)$ compared with users of other testing sites. The users tested at hotels also stand out, together with users being tested at the GLHN office, in regards to reporting never having tested for HIV before (24.0\% and $22.1 \%$ answered this, respectively).

Regarding motivations for choosing to get tested for HIV at Sjekkpunkt Norway, table 3 shows that most reported the possibility of getting an HIV rapid test as their motivation (61.7\%). The other motivations reported were; opening hours $(37.3 \%)$, location $(31.0 \%)$, anonymity $(28.1 \%)$, that Sjekkpunkt Norway is not located in a doctor's office/hospital $(7.1 \%)$ and that the testing does not involve medical practices $(5.6 \%)$.

\section{Discussion}

Sjekkpunkt Norway is designed with the aim to increase HIV testing among MSM by recruiting users from the target population not attending already existing testing services, as well as other MSM with risk of getting HIV. The study results indicate that a low-threshold testing service like Sjekkpunkt Norway is able to recruit important target groups that are otherwise hard to reach with HIV testing, such as MSM with non-western immigrant backgrounds, MSMW and other MSM at high risk for HIV. Also, that a large proportion have never tested for HIV before or that their last HIV test was 2 years ago or more, indicates that this mode of offering HIV tests appeals to target groups such as the above mentioned. The differences in demographical and sexually behavioural characteristics of the users according to testing site show the importance of the project's outreach component. Users tested at a sauna/ on cruising areas were generally older and reported more male sexual partners compared with users at other testing sites. Those tested at hotels were more likely than others (eg, users at the GLHN office) never to have been tested for HIV. They also were more likely to have practised UAI compared with users of the other testing sites.

This study has several limitations. First, as recruitment to the study is based on self-selection; the HIV testing behaviour, social demographic and sexually behavioural characteristics of the users of Sjekkpunkt Norway may differ over time. Another limitation is that the small size of some of the subgroups, especially those getting tested at gay bars/clubs, gay saunas and cruising areas and to some extent those getting tested at hotels, might have influenced the results of this study. A third limitation is that the study, as all other studies on sexual health, must rely on self-reported data on sexual behaviour which is subject to recall and desirability bias, ${ }^{2324}$ such as under-reporting number of male sexual partners and other homosexual experiences. Data obtained from this survey should be regarded as reported behaviour rather than actual behaviour. These limitations are important to keep in mind when discussing the results.

The different low-threshold HIV testing services that has been established during the last decade, such as those in France, ${ }^{4}$ Germany, ${ }^{25}$ Spain $^{5}$ and Denmark, ${ }^{26}$ are most often community based, which in this instance means that they were started by gay organisations, run by institutions with gay or LGBT profiles or by institutions for gay people living with HIV. In contrast to this, Sjekkpunkt Norway is organised with the intention of appearing as discrete and neutral as possible and without any connection to gay communities and/ or organisations. This may explain why, compared with the testing services in France, Germany and Spain, the proportion of bisexual and straight MSM testing for HIV is somewhat larger at Sjekkpunkt Norway. However, the low-threshold HIV testing service in Denmark, which is community based, stands out with a larger proportion of straight MSM (11\%) compared with the users of Sjekkpunkt Norway. ${ }^{26}$ Nevertheless, a limitation of this Danish study is its uncertainty regarding whether the respondents have answered the survey on several occasions. It is therefore problematic to compare prevalences from this study with the results from other studies.

The neutral aspect of Sjekkpunkt Norway is most prominent when the testing service is located at hotels, which may be why the largest proportion of non-gay 


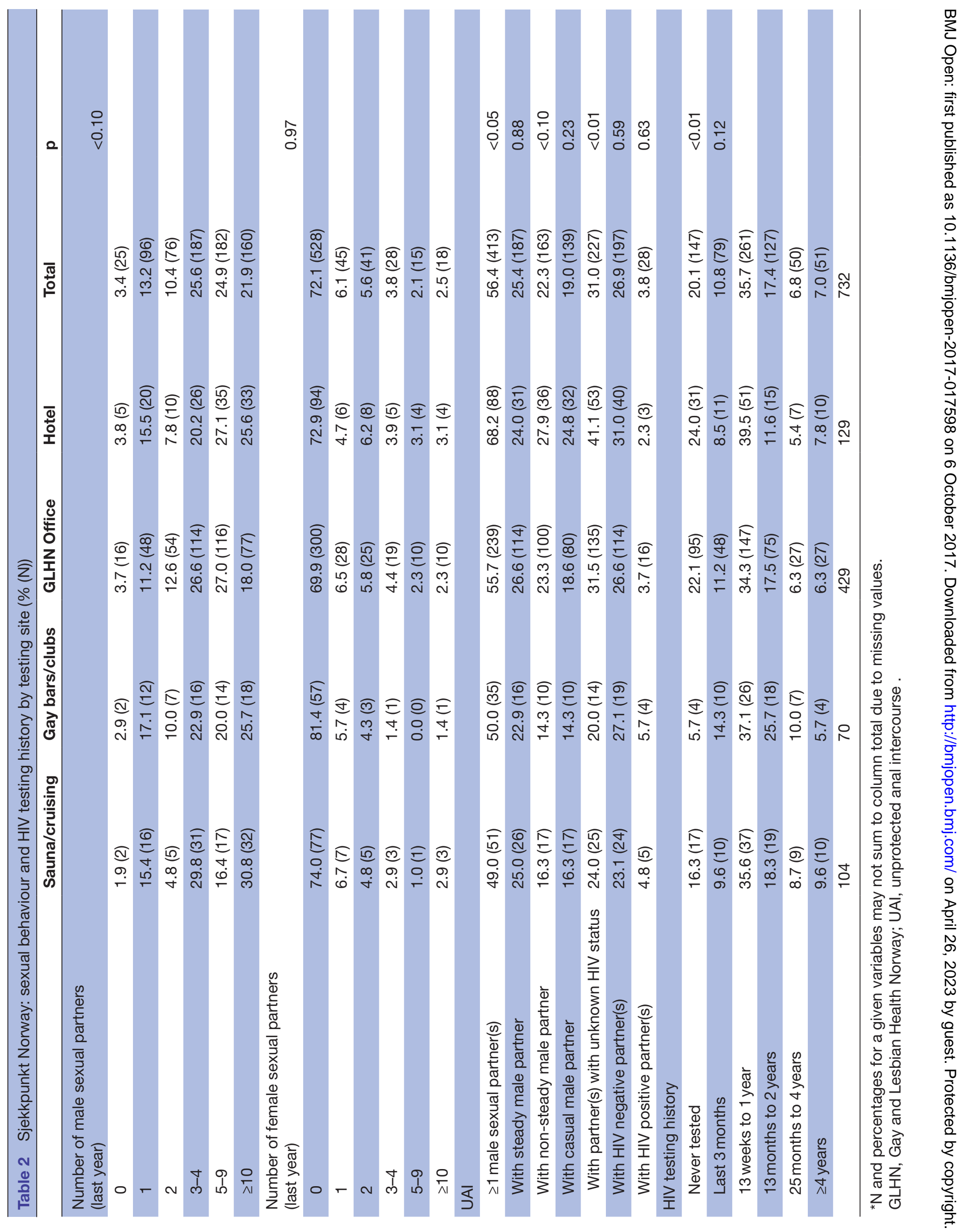


Table 3 Motivations for choosing to test at Sjekkpunkt Norway

\section{(Multiple choice) \% (N)}

All MSM users $(n=732)$

Why did you choose to test at Sjekkpunkt Norway?

$\begin{array}{ll}\text { The rapid test } & 61.7(452) \\ \text { Opening hours } & 37.3(273) \\ \text { Location } & 31.0(227) \\ \text { The testing is anonymous } & 28.1(206) \\ \text { Not a doctor's office/hospital } & 7.1(52) \\ \text { Not medical practices } & 5.6(41)\end{array}$

Missing values for 114 (15.5\%) observations (included in the calculation of percentages).

MSM, men who have sex with men.

identifying MSM chose to get tested at this testing site specifically. This difference, however, was not statistically significant. This may be a reflection of the small size of the subgroups being compared. Furthermore, that those who had never tested for HIV before were more likely to get tested at hotels, and the GLHN office may also be a consequence of the neutrality of these testing sites compared with the testing performed at saunas, cruising areas and gay bars/clubs. Overall, the proportion reporting never having been tested for HIV before at Sjekkpunkt Norway is also larger than in similar testing services in Germany (13\%) and Denmark (12\%). Regarding respondents reporting having practised UAI, the proportion is large among the users of Sjekkpunkt Norway. This however, is difficult to compare with other studies of similar testing services, as different measures on UAI are used or the results are not reported.

To sum up, the results indicate that a complex testing service, such as Sjekkpunkt Norway, combining mobility by being present at traditional gay venues as well as more neutral locations, not associated with LGBT communities or organisations, is able to recruit difficult-to-reach groups in the MSM population to HIV testing. These results suggest that new modes of HIV testing, especially testing services aiming for a neutral and discrete profile, should be explored further as they can be important means to address the significant challenges of the HIV epidemic, particularly regarding efforts to increase HIV testing rates among MSM.

Contributors BUM and VB contributed substantially to conception, design and acquisition of data. BUM was responsible of the management of data. BUM and VB performed the analyses and interpretations of the data. BUM and VB contributed equally to the drafting of the article and revised it critically for important intellectual content and final approval of the version to be published.

Competing interests All authors have completed the ICMJE uniform disclosure format www.icmje.org/coi disclosure.pdf and declare: no support from any organisation for the submitted work; no financial relationships with any organisations that might have an interest in the submitted work in the previous three years; no other relationships or activities that could appear to have influenced the submitted work.

Provenance and peer review Not commissioned; externally peer reviewed.
Data sharing statement The study was approved and assessed as not being notifiable by the Norwegian Center for Research Data (NSD) and the Regional Committees for Medical and Health Research Ethics (REC). One condition for the approval was that no-one other than the authors had access to the data due to anonymity concerns.

Open Access This is an Open Access article distributed in accordance with the Creative Commons Attribution Non Commercial (CC BY-NC 4.0) license, which permits others to distribute, remix, adapt, build upon this work non-commercially, and license their derivative works on different terms, provided the original work is properly cited and the use is non-commercial. See: http://creativecommons.org/ licenses/by-nc/4.0/

(c) Article author(s) (or their employer(s) unless otherwise stated in the text of the article) 2017. All rights reserved. No commercial use is permitted unless otherwise expressly granted.

\section{REFERENCES}

1. Jakopanec I, Grjibovski AM, Nilsen Ø, et al. Trends in HIV infection surveillance data among men who have sex with men in Norway, 1995-2011. BMC Public Health 2013;13:144.

2. Grulich AE, Kaldor JM. Trends in HIV incidence in homosexual men in developed countries. Sex Health 2008:5:113-8.

3. Sullivan PS, Hamouda O, Delpech V, et al. Reemergence of the HIV epidemic among men who have sex with men in North America, Western Europe, and Australia, 1996-2005. Ann Epidemiol 2009;19:423-31.

4. Champenois K, Le Gall JM, Jacquemin C, et al. ANRS-COM'TEST: description of a community-based HIV testing intervention in non-medical settings for men who have sex with men. BMJ Open 2012;2:e000693

5. Ferrer L, Loureiro E, Meulbroek M, et al. High HIV incidence among men who have sex with men attending a community-based voluntary counselling and testing service in Barcelona, Spain: results from the ITACA cohort. Sex Transm Infect 2016;92:70-5.

6. Lorente N, Fernàndez-López L, Fuertes R, et al. Euro HIV EDAT Study Group. COBA-Cohort: a prospective cohort of HIV-negative men who have sex with men, attending community-based HIV testing services in five European countries (a study protocol). BMJ Open 2016;6:e011314

7. Meireles P, Lucas R, Martins A, et al. The Lisbon Cohort of men who have sex with men. BMJ Open 2015;5:e007220.

8. Nardone A, Delpech V, Gill ON, et al. HIV in the UK: test, test, and test again. Lancet 2013;382:1687-8.

9. Phillips AN, Cambiano V, Miners A, et al. Potential impact on HIV incidence of higher HIV testing rates and earlier antiretroviral therapy initiation in MSM. AIDS 2015;29:1855-62.

10. Clifton S, Nardone A, Field N, et al. HIV testing, risk perception, and behaviour in the British population. AIDS 2016;30:943-52.

11. Mercer $\mathrm{CH}$, Fenton KA, Copas AJ, et al. Increasing prevalence of male homosexual partnerships and practices in Britain 1990-2000: evidence from national probability surveys. AIDS 2004:18 10:1453 58.

12. Mercer $\mathrm{CH}$, Prah P, Field $\mathrm{N}$, et al. The health and well-being of men who have sex with men (MSM) in Britain: evidence from the third National Survey of Sexual Attitudes and Lifestyles (Natsal-3). BMC Public Health 2016;16:525.

13. Folkehelseinsituttet. Hivsituasjonen i Norge hittil i 2014. Oslo, 2014 https://www.fhi.no/tm/div/nyheter3/hivsituasjonen-i-norge-hittil-i201/ (accessed 13 Oct 2016).

14. Prosjektteamet EMIS Norge. Rapport fra EMIS 2010 - Europeisk menn som har sex med menn internettundersøkelse: Norske resultater: EMIS, 2012.

15. Jakopanec I, Schimmer B, Grjibovski AM, et al. Self-reported sexually transmitted infections and their correlates among men who have sex with men in Norway: an Internet-based cross-sectional survey. BMC Infect Dis 2010;10:261.

16. Prah P, Hickson F, Bonell C, et al. Men who have sex with men in Great Britain: comparing methods and estimates from probability and convenience sample surveys. Sex Transm Infect 2016;92:455-63.

17. Copen CE, Chandra A, Febo-Vazquez I. National Center for Health Statistics. HIV testing in the past year among the US household population aged 15-44: 2011-2013. 2015. NCHS data brief no 202 (accessed 12 Oct 2016).

18. Sonnenberg P, Clifton S, Beddows S, et al. Prevalence, risk factors, and uptake of interventions for sexually transmitted infections in Britain: findings from the National Surveys of Sexual Attitudes and Lifestyles (Natsal). The Lancet 2013;382:1795-806. 
19. Conway DP, Holt M, Couldwell DL, et al. Barriers to HIV testing and characteristics associated with never testing among gay and bisexual men attending sexual health clinics in Sydney.J Int AIDS Soc 2015; 18

20. Spielberg F, Branson BM, Goldbaum GM, et al. Overcoming barriers to HIV testing: preferences for new strategies among clients of a needle exchange, a sexually transmitted disease clinic, and sex venues for men who have sex with men. J Acquir Immune Defic Syndr 2003;32:318-27.

21. Dyer TP, Regan R, Pacek LR, et al. Psychosocial vulnerability and HIV-related sexual risk among men who have sex with men and women in the United States. Arch Sex Behav 2015;44:429-41.

22. Folkehelseinstituttet. Hivsituasjonen i Norge per 31. dec 2015. Oslo, 2016. https://www.fhi.no/globalassets/dokumenterfiler/rapporter/ hivsituasjonen-i-norge-per-31.12.2015.pdf. (accessed 13 Oct 2016).
23. Mercer $\mathrm{CH}$. Measuring sexual behaviour and risk. $2010 \mathrm{https} / / / \mathrm{www}$. ukdataservice.ac.uk/media/262883/discover_sqb_sex_mercer.pdf (accessed 27 apr 2016).

24. Mitchell KR, Mercer $\mathrm{CH}$, Ploubidis GB, et al. Sexual function in Britain: findings from the third National Survey of Sexual Attitudes and Lifestyles (Natsal-3). The Lancet 2013;382:1817-29.

25. Marcus U, Ort J, Grenz M, et al. Risk factors for HIV and STI diagnosis in a community-based HIV/STI testing and counselling site for men having sex with men (MSM) in a large German city in 2011 2012. BMC Infect Dis 2015;15:14.

26. Qvist T, Cowan SA, Graugaard C, et al. High linkage to care in a community-based rapid HIV testing and counseling project among men who have sex with men in copenhagen. Sex Transm Dis 2014;41:209-14. 